\title{
Outcomes of the Ulnar Shortening Osteotomy Using a Dynamic Compression Plate on the Ulnar Surface of the Ulna
}

\author{
Ahmed Elgammal, $\mathrm{PhD}^{1,2}$ Bernhard Rozée, $\mathrm{MD}^{3}$ \\ ${ }^{1}$ Department of Orthopedics, Ain Shams University Hospitals, \\ Al Waili, Cairo, Egypt \\ 2 Department of Hand Surgery, Helios Kliniken, München, Germany \\ ${ }^{3}$ Department of Hand Surgery, Hessing Klinik, Augsburg, Germany
}

\author{
Address for correspondence Ahmed Elgammal, PhD, Helios Kliniken, \\ Perlacher Street 32, München, 81539, Germany \\ (e-mail: ahmedelgammal@hotmail.de).
}

J Wrist Surg 2018;7:344-349.

\begin{abstract}
Background The purpose of this study is to evaluate the results of patients with ulnar impaction syndrome treated with diaphyseal osteotomy using freehand technique and fixation with ulnar osteotomy compression plate placed on the ulnar surface of the ulna. Materials and Methods A retrospective chart review of patients with ulnar impaction syndrome between 2010 and 2014 identified 38 patients. The following clinical data were observed: patient age, sex, range of motion, grip strength, visual analog scale (VAS), Disabilities of the Arm, Shoulder, and Hand (DASH) score, radiological assessment, and complications. The mean follow-up period is 30 months. Eleven patients were excluded from the study.

Keywords

- ulnar shortening osteotomy

- ulnar impaction syndrome

- triangular fibrocartilage complex

- chondromalacia

Results Compared with the contralateral side, the 27 patients included in this study attained 93 to $96 \%$ of wrist and forearm motion and $81 \%$ of the grip strength. The average DASH score was 18 in a mean follow-up period of 30 months. Three patients required plate removal and one case showed nonunion and a further operation was needed. Two patients reported persistent ulnar-sided wrist pain.

Conclusion We concluded that placing the ulnar osteotomy plate on the ulnar surface of the ulna is a quicker procedure, with less soft tissue dissection and irritation, and very high union rate.

Level of Evidence Level IV.
\end{abstract}

Ulnar impaction syndrome was described by Friedman and Palmer ${ }^{1}$ as degenerative changes of the ulnar aspect of the wrist in patients with positive ulnar variance either static or dynamic. The chronic load between the ulnar head, the triangular fibrocartilage complex (TFCC), and the ulnar carpus results in cartilaginous lesions of the lunate and ulnar head, lunatotriquetral ligament disruption, and degeneration of the TFCC. ${ }^{2-4}$

Ulnar impaction syndrome is either idiopathic or secondary. In patients with congenital or dynamic positive ulnar variance with wrist pronation and forceful grip with no history of fracture or premature physael arrest, the condition is termed

received

May 6, 2017

accepted after revision

October 20, 2017

published online

December 14, 2017 idiopathic. Patients suffering from ulnar impaction syndrome report ulnar-sided wrist pain exacerbated by forearm rotation or ulnar deviation of the wrist during daily activities. ${ }^{5}$

The characteristic plain radiographic findings associated with idiopathic ulnar impaction syndrome include positive ulnar variance and radiographic carpal chondromalacia, evidenced by cortical sclerosis or subchondral changes consistent with cystic changes in the ulnar head, ulnar corner of the lunate, and/or radial corner of the triquetrum. ${ }^{5,6}$ Progressive abutment of the ulnocarpal junction may result in progressive cartilaginous erosions of the lunate and ulnar head, lunatotriquetral ligament disruption, and degeneration of the TFCC. ${ }^{2-4}$
Copyright $\odot 2018$ by Thieme Medical Publishers, Inc., 333 Seventh Avenue, New York, NY 10001, USA. Tel: +1(212) 584-4662.
DOI https://doi.org/ 10.1055/s-0037-1608851. ISSN 2163-3916. 
Ulnar shortening osteotomy is the method of choice to decompress the ulnocarpal joint to relieve the symptoms of ulnar impaction by restoring neutral or negative ulnar variance. ${ }^{4,6} \mathrm{~A}$ variety of surgical techniques have been described, with the goal of optimizing the ulnar variance. This article reports the outcomes of ulnar shortening osteotomy using a dynamic compression system after creation of an oblique ulnar diaphyseal osteotomy in a freehand technique and placing the plate on the ulnar surface of the ulna to avoid disturbing the muscle originating from the volar or dorsal surface of the ulna and making use of the flat ulnar surface which accommodate the plate with minimal soft tissue dissection.

\section{Materials and Methods}

After review approval, we performed a retrospective review of patients diagnosed with ulnar impaction syndrome. We identified 38 patients who have ulnar shortening osteotomy with locked dynamic compression plate at our institution between 2010 and 2014. Inclusion criteria includes patient with positive ulnar variance of at least $2 \mathrm{~mm}$, with evidence of ulnar impaction lesions on magnetic resonance imaging like chondromalacia of the lunate, triquetrum with failure of conservative treatment over a period of 6 months. Patient with secondary ulnar impaction syndrome, that is, malunited distal radius (three cases) or Madelung's deformity (two cases), were excluded. Six patients were excluded from the study either because of associated secondary pathology which was operated (four cases) or they do not show up in the follow-up clinics (two cases).

A total of 27 patients were included in this study, 19 females and 8 males. The average age was 50 (18-79, SD 15) years. The dominant hand was affected in 18 patients. The mean follow-up period was 30 (12-47) months.

We performed wrist arthroscopy for all the patients immediately before the osteotomy to evaluate the condition of the TFCC, the lunatotriquetral interosseous ligament, and the condition of the lunate and triquetrum articular surfaces. The osteotomy was done using the freehand technique and the ulnar shortening plate was placed on the ulnar surface of the ulna. The patients were immobilized after surgery in a short arm splint for 6 weeks, and physiotherapy was performed on the patients out of the splint from day 1 , including rotational movement postoperatively.

Subjective and objective assessment includes visual analog scale (VAS) pre- and postoperatively in which 0

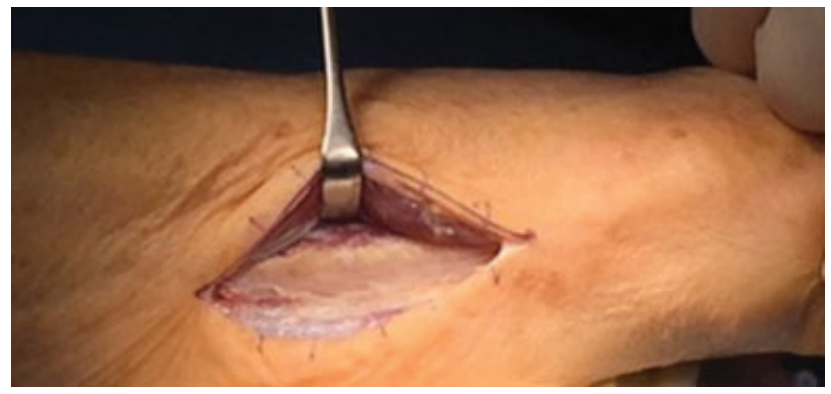

Fig. 1 Approach and exposure of the ulna.

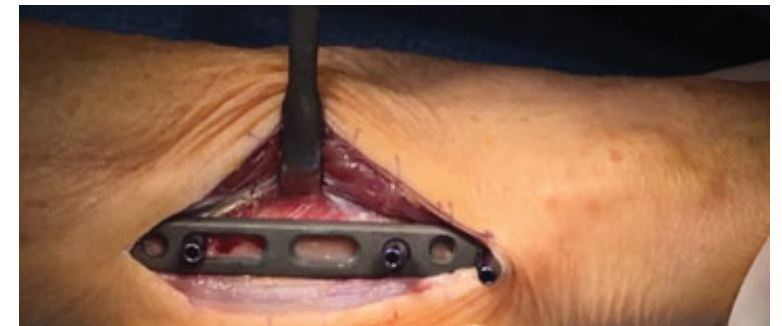

Fig. 2 Application of the ulnar osteotomy plate.

represented no pain and 10 represented severe pain. The Disabilities of the Arm, Shoulder, and Hand (DASH) questionnaire was used to evaluate the upper extremity function pre- and postoperatively.

Active range of motion (ROM) included wrist flexion/extension for the affected and contralateral limbs and forearm pronation/supination for the affected and contralateral limbs.

Grip strength (Jamar Hydraulic Hand Dynamometer, Jamar Technologies) was evaluated for both limbs, without correction for hand dominance. These measures were recorded for the 27 patients who maintained regular follow-up appointments. Intraoperative information or postoperative complications was also retrieved from the patient database.

Radiological assessment of the forearm with wrist joint in two views was performed after 6 to 18 weeks and at final follow-up. We assessed the consolidation and nonunion rate radiologically. We also analyzed complication of the surgery.

Variations in the outcome within the study group were assessed statistically using one-way analysis of variance (ANOVA). Statistical significance was accepted at $p<0.05$ level (StatPlus: statistical analysis program for Mac OS, Version 2009).

\section{Surgical Technique}

An ulnar incision of $8 \mathrm{~cm}$ long is made starting $5 \mathrm{~cm}$ proximal to the ulnar head, opening the fascia between flexor and extensor carpi ulnaris muscle, and identifying the ulnar surface of the ulna without disturbing the muscle origin from the volar or dorsal surface of the ulna (-Fig. 1). The locked plate is applied on the ulnar surface of the ulna and the plate orientation is confirmed using fluoroscopy (-Fig. 2). Distal locked screws are drilled and inserted in the first and third hole, and two proximal cortical screws are applied in the proximal aspect of the gliding hole without tightening the screw to the far cortex ( - Fig. 3 ).

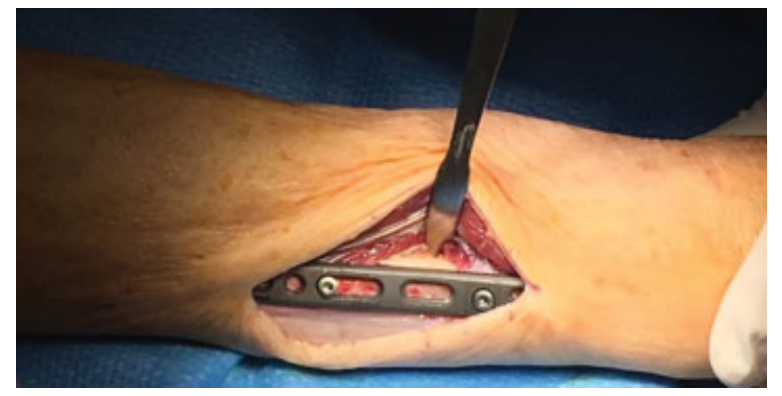

Fig. 3 The osteotomy site is well marked. 


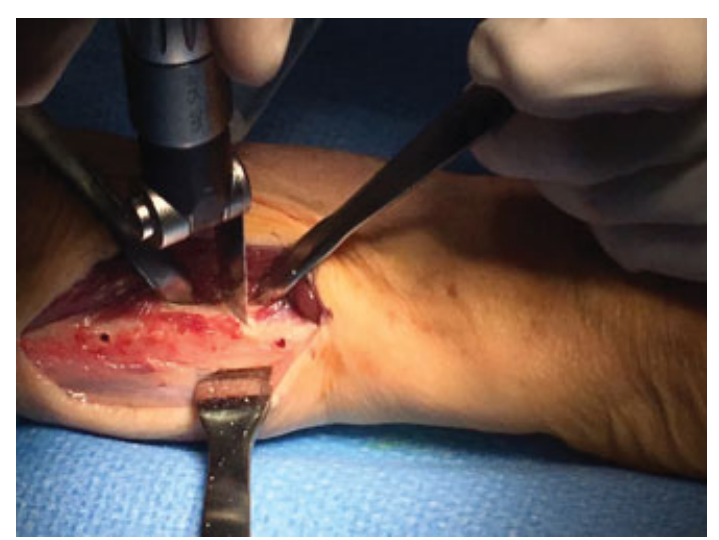

Fig. 4 Distal osteotomy.

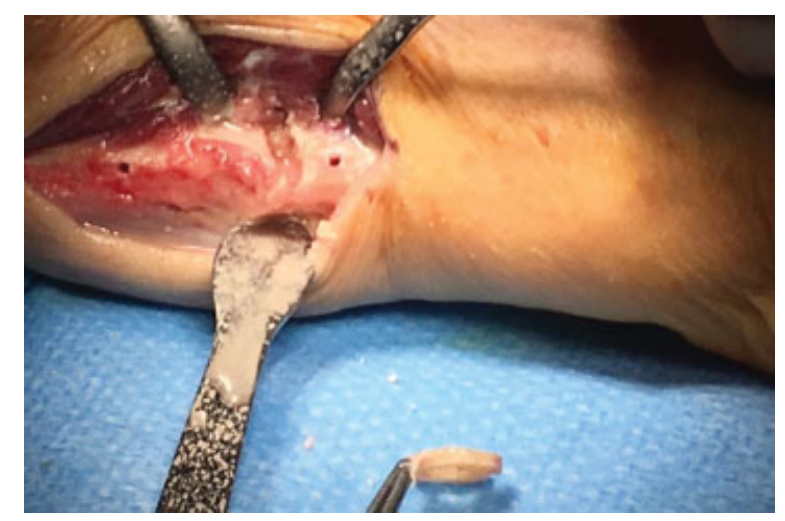

Fig. 6 Osteotomy site after removal of the bone.

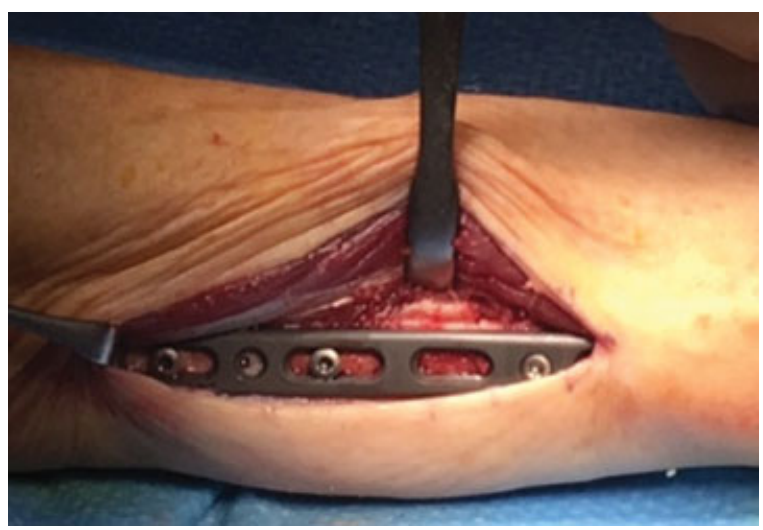

Fig. 8 Insertion of the proximal and distal screws.

The osteotomy level is identified and marked and the plate is temporarily removed. Minimal dissection is performed and muscle fibers are removed from the osteotomy site, and Homan's test is applied to protect the volar and dorsal soft tissue (-Figs. 4 and 5). Osteotomy is done at the previously marked level with cooling and the amount of bone removed depended on the preoperative measurements ( - Fig. 6). The plate is reapplied and the previously drilled distal locking screws are inserted, and then the proximal placed screws are reinserted without tightening. A reduction clamp is used to close the osteotomy (-Fig. 7), and then the most proximal

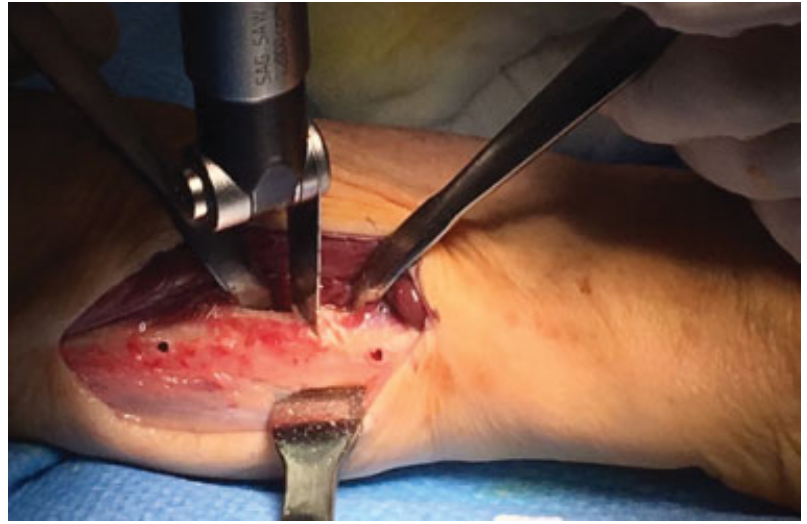

Fig. 5 Proximal osteotomy.

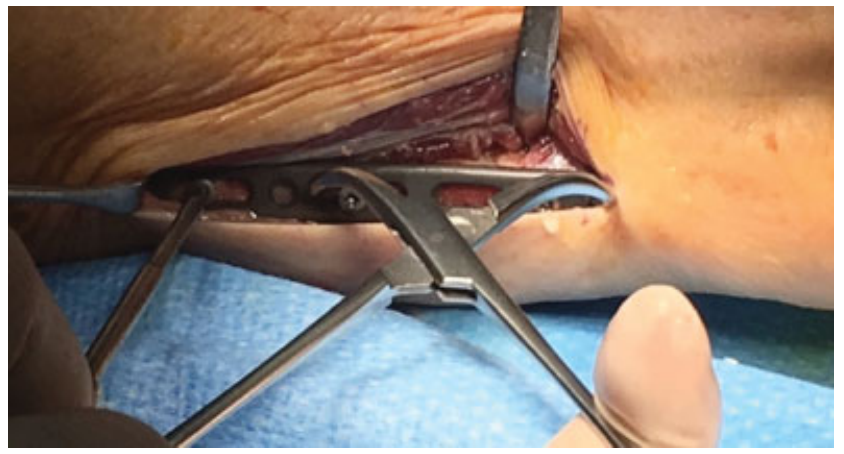

Fig. 7 Compression of the osteotomy site.

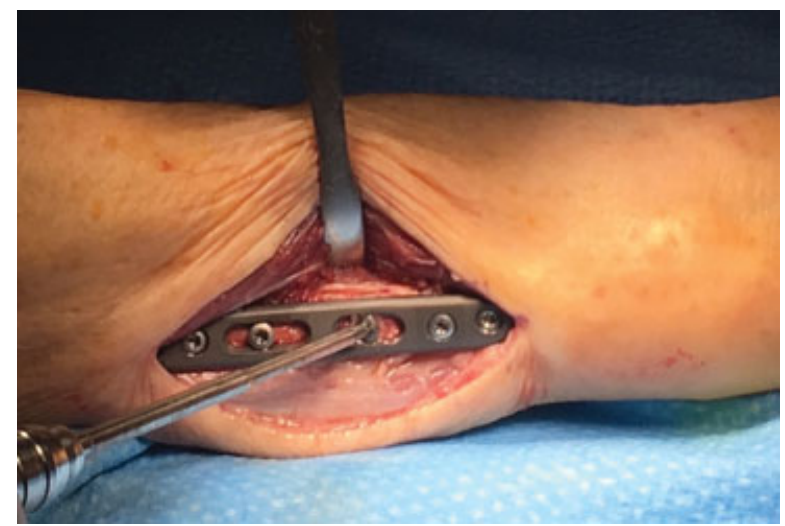

Fig. 9 Application of the lag screw.

cortical screw is tightened (-Fig. 8). And then the insertion of the proximal and distal screws is completed. At the end, the lag screw is drilled and inserted at $60^{\circ}$ angle across the osteotomy site (-Fig. 9). The amount of shortening achieved is confirmed using fluoroscopy (-Figs. 10, 11A-C, and 12), and closed in layers and a forearm slab applied.

\section{Results}

12 palmer $2 \mathrm{C}$ tears, $52 \mathrm{D}, 52 \mathrm{~B}, 32 \mathrm{E}$ and two patients $2 \mathrm{~A}$ are shown in - Tables $\mathbf{1}$ and $\mathbf{2}$. These injuries were treated with 


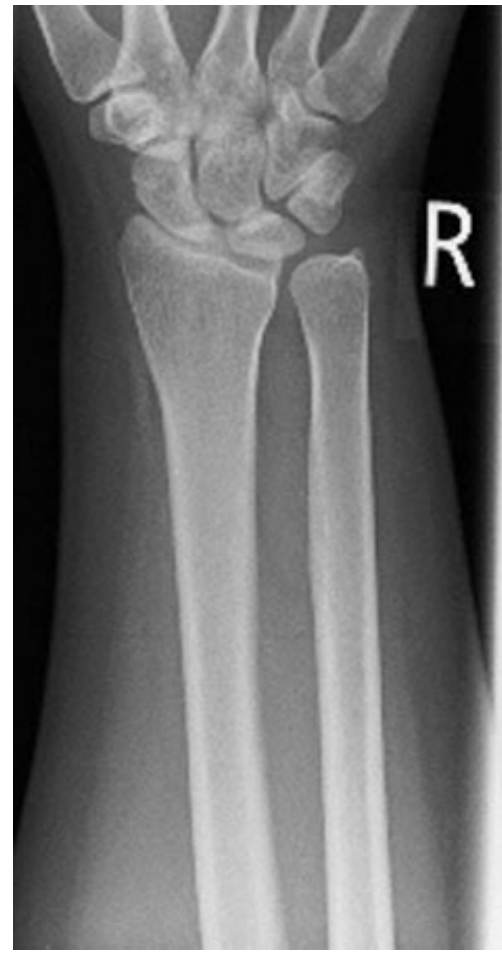

Fig. 10 Preoperative X-ray showing ulnar impaction.

arthroscopic debridement followed by the ulnar shortening osteotomy.

The mean VAS improved from 7 (range, 3-10; SD, 2) preoperatively to 3 (range, $0-10 ; S D, 3$ ) postoperatively. Function measured with the DASH score had improved from 45 (range, 20-71; SD, 14) to 18 (range, 0-62; SD, 18) (- Table 3).

The average ROM in flexion and extension was $95 \%$ of the contralateral side and in forearm rotation, and the average range of pronation was $96 \%$ of the contralateral side and in supination was $93 \%$ of the contralateral side ( - Table 4 ).

Mean grip strength at last follow-up was $87 \%$ compared with the contralateral side (range, 30-100\%).

Mayo wrist score showed 12 excellent, 7 very good, 3 satisfactory, and 4 poor results.

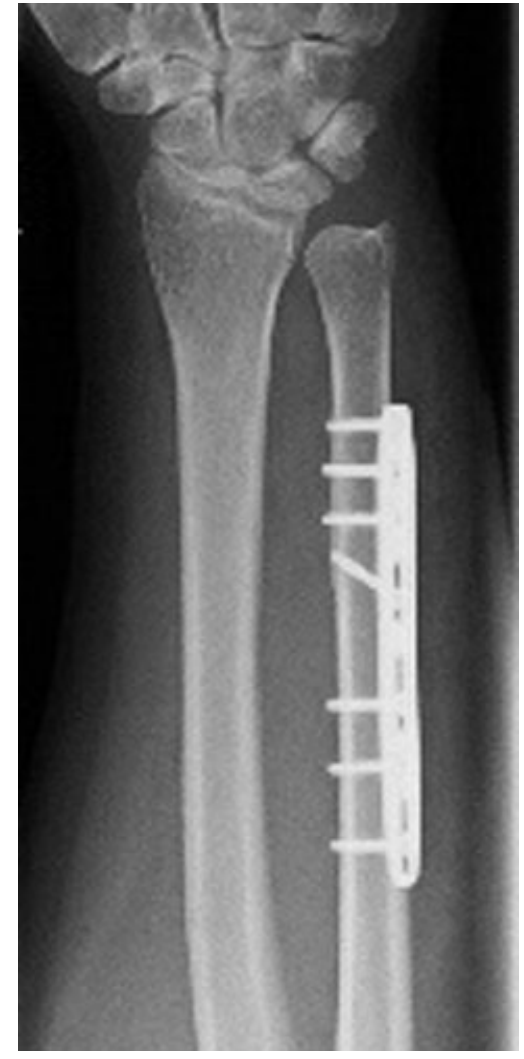

Fig. 12 Postoperative X-ray.

The amount of ulnar shortening was between 2 and $4 \mathrm{~mm}$. The operation time for the ulnar shortening osteotomy was 39 minutes in average (range, 31-50; SD, 4).

Note that $23 / 27$ of our patients were satisfied with the results and would agree to do the operation once more. No patient in our study group has to change his job or preoperative activities.

We had six complications. Three patients suffered irritation from plate prominence at 1 year. One showed nonunion and revision was done. Two patients complained of persistent ulnar-sided wrist pain. After exclusion of the nonunion case,
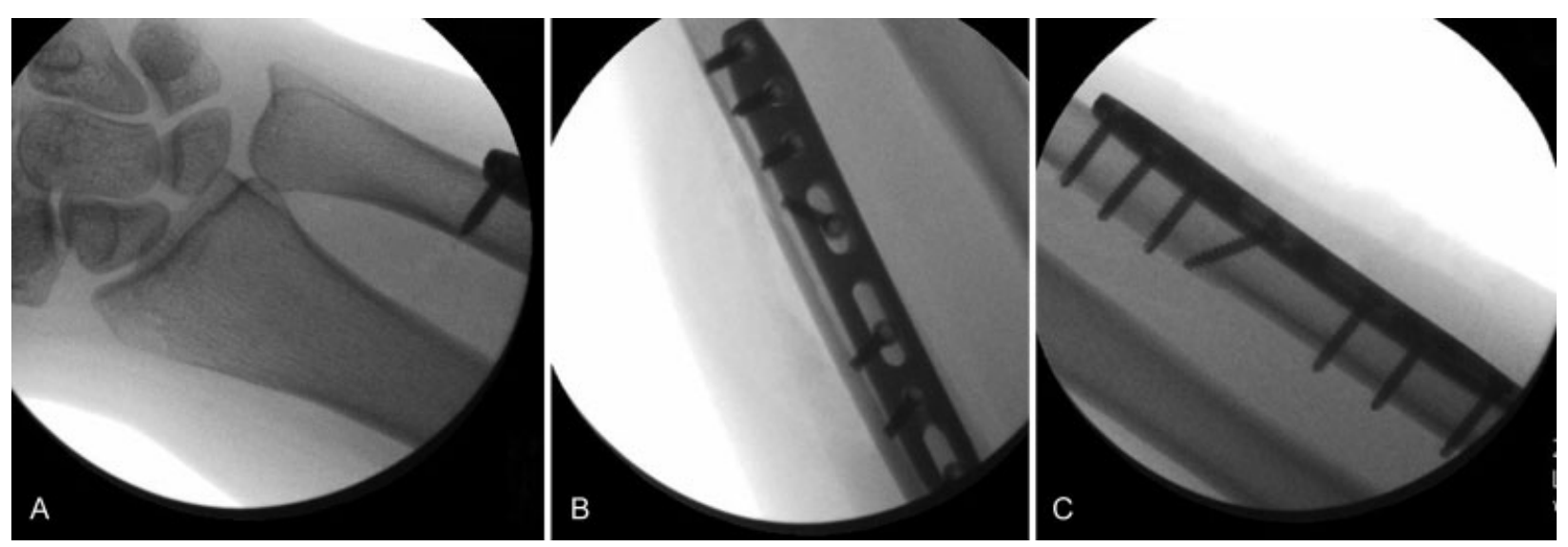

Fig. 11 (A-C) Intraoperative X-ray after osteotomy. 
Table 1 Arthroscopic palmer classification

\begin{tabular}{|l|l|}
\hline Palmer classification & Number of patients \\
\hline IIA & 2 \\
\hline IIB & 5 \\
\hline IIC & 12 \\
\hline IID & 5 \\
\hline IIE & 3 \\
\hline
\end{tabular}

Table 2 Outerbridge stage of lunate chondromalacia through arthroscopy

\begin{tabular}{|l|l|}
\hline Outerbridge staging & Number of patients \\
\hline I & 5 \\
\hline II & 14 \\
\hline III & 5 \\
\hline IV & 3 \\
\hline
\end{tabular}

Table 3 Clinical outcomes after ulnar shortening osteotomy

\begin{tabular}{|l|l|l|l|}
\hline & $\begin{array}{l}\text { Preoperative } \\
\text { mean, range, } \\
\text { and SD }\end{array}$ & $\begin{array}{l}\text { Postoperative } \\
\text { mean, range, } \\
\text { and SD }\end{array}$ & $p$-Value \\
\hline $\begin{array}{l}\text { Ulnar } \\
\text { variance }\end{array}$ & $\begin{array}{l}2.5 \\
(2-4.2 ; 0.6)\end{array}$ & $\begin{array}{l}0.3 \\
(0-1 ; 0.4)\end{array}$ & $<0.05$ \\
\hline VAPS & $7(3-10 ; 2)$ & $\begin{array}{l}3 \\
(0-10 ; 3)\end{array}$ & $<0.05$ \\
\hline $\begin{array}{l}\text { DASH } \\
\text { score }\end{array}$ & $\begin{array}{l}45 \\
(20-71 ; 14)\end{array}$ & $\begin{array}{l}18 \\
(0-62 ; 18)\end{array}$ & $<0.05$ \\
\hline
\end{tabular}

Abbreviations: DASH score, Disabilities of the Arm, Shoulder, and Hand score; VAPS, visual analog pain score; SD, standard deviation.

Table 4 Postoperative range of motion compared with the opposite side

\begin{tabular}{|l|l|l|}
\hline & Postoperative & Contralateral (\%) \\
\hline Wrist flexion & $65^{\circ}$ & $95 \%$ \\
\hline Wrist extension & $70^{\circ}$ & $95 \%$ \\
\hline Forearm pronation & $82^{\circ}$ & $96 \%$ \\
\hline Forearm supination & $78^{\circ}$ & $93 \%$ \\
\hline
\end{tabular}

the average time to union after ulnar shortening osteotomy was 8 weeks (range, 6-18 weeks).

\section{Discussion}

In this series, we obtained excellent clinical outcomes in ulnocarpal impaction syndrome with our technique. The postoperative ROM was not less than $95 \%$ of the contralateral side. The VAS improved from average of 7 preoperatively to 3 postoperatively, with $16 / 26(60 \%)$ of patients reporting to have no or very mild pain (- Table 5). ${ }^{7}$ Many techniques of ulnar shortening osteotomy were described by different authors, with variations in the location, orientation of the osteotomy, and variation in plate positioning regarding size and location. The standard method is performing diaphyseal osteotomy, but several authors reported good results with metaphyseal osteotomy as well, reporting better union rates and less soft tissue irritation. ${ }^{8-10}$

Diaphyseal osteotomies have the advantage of improving radioulnar stability because of the tensioning effect on the distal interosseous ligament. ${ }^{11}$ Oblique, ${ }^{12}$ transverse, ${ }^{13}$ and step-cut osteotomy have been described. ${ }^{8}$

Rayhack et al $^{14}$ showed a significantly shorter time to union with oblique osteotomy. Wehbé and Cautilli ${ }^{15}$ reported similar healing times with a transverse osteotomy.

Most studies reported using $3.5-\mathrm{mm}$ or similarly sized plates. $^{7,8,12,14,16}$ Chun and Palmer ${ }^{12}$ recommended dorsal plate placement, whereas others advocate volar plate placement. ${ }^{13,16}$

In this study, we present a technique with ulnar plate placement, with the advantage of minimal soft tissue dissection, which might have a positive effect on healing in addition to minimizing the operation time. Our average operation time was minimized the irritation of the flexor carpi ulnaris and ulnar sided flexor digitorum profundus tendons, the postoperative grip strength.

Another advantage is to minimize the possible screw irritation of the volar or dorsal muscle mass by the application of the plate on the ulnar surface.

Although volar plate application is recommended by several authors, ${ }^{13,16}$ painful hardware irritation was found. In the study of Ahsan et al, ${ }^{17} 4$ of 30 (13\%) patients required plate removal. Loh et $\mathrm{al}^{4}$ in a review of 22 patients did plate removal for 7 patients (32\%). Chen and Wolfe ${ }^{16}$ reported that $8 / 18(44 \%)$ of the patients requested plate removal. Pomerance ${ }^{18}$ removed plates in 14 of 40 patients (35\%), and Lauder et al ${ }^{19}$ reported 4 cases $(24 \%)$ of plate removal in a cohort of 17 patients. Not only

Table 5 Comparison with other studies in the literature

\begin{tabular}{|l|l|l|l|l|l|l|l|l|l|}
\hline & No & $\begin{array}{l}\text { Follow-up } \\
(\mathrm{mo})\end{array}$ & $\begin{array}{l}\text { Nonunion } \\
(\mathbf{n})\end{array}$ & $\begin{array}{l}\text { Plate } \\
\text { removal }\end{array}$ & Flexion & Extension & Pronation & $\begin{array}{l}\text { Supination } \\
\begin{array}{l}\text { Grip } \\
\text { strength } \\
(\mathrm{kg})\end{array}\end{array}$ \\
\hline Our study & 27 & 30 & $1(2.5)$ & $3(11 \%)$ & $58^{\circ}$ & $64^{\circ}$ & $82^{\circ}$ & $78^{\circ}$ \\
\hline Ahsan et al $^{17}$ & 30 & 8 & $2(7 \%)$ & $4(13 \%)$ & $74^{\circ}$ & $65^{\circ}$ & $77^{\circ}$ & $73^{\circ}$ & 26 \\
\hline $\begin{array}{l}\text { Das De et al } \\
\text { (Dorsal plating) }\end{array}$ & 16 & 12 & $0(0 \%)$ & $1(6 \%)$ & $68^{\circ}$ & $68^{\circ}$ & $79^{\circ}$ & $76^{\circ}$ & 31 \\
\hline $\begin{array}{l}\text { Das De et al } \\
\text { (Volar plating) }\end{array}$ & 18 & 12 & $2(11 \%)$ & $6(33 \%)$ & $68^{\circ}$ & $59^{\circ}$ & $70^{\circ}$ & $73^{\circ}$ & 20 \\
\hline
\end{tabular}


can the volar plate application cause scarring and soft tissue irritation of the muscle mass but it can also cause persistent neuropathic changes of the dorsal sensory branch of the ulnar nerve which can require revision surgery.

In this study, we had only three cases of plate removal(11\%), which is of lower percentage compared with the former studies and no case of ulnar nerve neuropathy was reported.

Another advantage is to use the anatomical flat surface of the ulna at this location, which can easily accommodate the ulnar shortening compression plate with slight contouring to increase compression.

The incidence of nonunion after ulnar shortening osteotomy has been reported in up to $13 \%$ cases in a study by Koppel et al. ${ }^{21}$ In another study, Rayhack et al ${ }^{14}$ reported one case of nonunion in a cohort of 17 patients (6\%). Ahsan et $\mathrm{al}^{17}{ }^{17}$ in his study, reported nonunion after ulnar shortening osteotomy in $2 / 30$ ( $7 \%$ ) of his patients. In this study, we had only one case of nonunion in the 38 cases identified (2.5\%).

One limitation of this study is the small sample size. Another limitation is the absence of a control group. The patients in this study had persistent ulnar-sided wrist pain with radiographic evidence of positive ulnar variance and ulnar impaction lesions. These patients' symptoms were refractory to conservative therapy. However, as discussed by McBeath et al, ${ }^{22}$ symptomatic improvement following ulnar shortening osteotomy cannot be definitively attributed to the surgical intervention, as it may be the natural course of the illness, or the placebo effect. That is why a randomized, controlled trial with a larger patient population is needed to distinguish between surgical and nonsurgical techniques.

\section{Funding}

None.

\section{Conflict of Interest}

None.

\section{References}

1 Friedman SL, Palmer AK. The ulnar impaction syndrome. Hand Clin 1991;7(02):295-310

2 Boulas HJ, Milek MA. Ulnar shortening for tears of the triangular fibrocartilaginous complex. J Hand Surg Am 1990;15(03):415-420

3 Kitzinger HB, Karle B, Löw S, Krimmer H. Ulnar shortening osteotomy with a premounted sliding-hole plate. Ann Plast Surg 2007;58(06):636-639
4 Loh YC, Van Den Abbeele K, Stanley JK, Trail IA. The results of ulnar shortening for ulnar impaction syndrome. J Hand Surg [Br] 1999; 24(03):316-320

5 Escobedo EM, Bergman AG, Hunter JC. MR imaging of ulnar impaction. Skeletal Radiol 1995;24(02):85-90

6 Cerezal L, del Piñal F, Abascal F, García-Valtuille R, Pereda T, Canga A. Imaging findings in ulnar-sided wrist impaction syndromes. Radiographics 2002;22(01):105-121

7 Baek GH, Chung MS, Lee YH, Gong HS, Lee S, Kim HH. Ulnar shortening osteotomy in idiopathic ulnar impaction syndrome. Surgical technique. J Bone Joint Surg Am 2006;88(Suppl 1 Pt 2): 212-220

8 Kawano M, Nagaoka K, Fujita M, Fukumoto M. New technique for ulnar shortening osteotomy. Tech Hand Up Extrem Surg 1998; 2(04):242-247

9 Hammert WC, Williams RB, Greenberg JA. Distal metaphyseal ulnar-shortening osteotomy: surgical technique. J Hand Surg Am 2012;37(05):1071-1077

10 Greenberg JA, Werner FW, Smith JM. Biomechanical analysis of the distal metaphyseal ulnar shortening osteotomy. J Hand Surg Am 2013;38(10):1919-1924

11 Arimitsu S, Moritomo H, Kitamura T, et al. The stabilizing effect of the distal interosseous membrane on the distal radioulnar joint in an ulnar shortening procedure: a biomechanical study. J Bone Joint Surg Am 2011;93(21):2022-2030

12 Chun S, Palmer AK. The ulnar impaction syndrome: follow-up of ulnar shortening osteotomy. J Hand Surg Am 1993;18(01):46-53

13 Baek GH, Chung MS, Lee YH, Gong HS, Lee S, Kim HH. Ulnar shortening osteotomy in idiopathic ulnar impaction syndrome. J Bone Joint Surg Am 2005;87(12):2649-2654

14 Rayhack JM, Gasser SI, Latta LL, Ouellette EA, Milne EL. Precision oblique osteotomy for shortening of the ulna. J Hand Surg Am 1993;18(05):908-918

15 Wehbé MA, Cautilli DA. Ulnar shortening using the AO small distractor. J Hand Surg Am 1995;20(06):959-964

16 Chen NC, Wolfe SW. Ulna shortening osteotomy using a compression device. J Hand Surg Am 2003;28(01):88-93

17 Ahsan ZS, Song Y, Yao J. Outcomes of ulnar shortening osteotomy fixed with a dynamic compression system. J Hand Surg Am 2013; 38(08):1520-1523

18 Pomerance J. Plate removal after ulnar-shortening osteotomy. J Hand Surg Am 2005;30(05):949-953

19 Lauder AJ, Luria S, Trumble TE. Oblique ulnar shortening osteotomy with a new plate and compression system. Tech Hand Up Extrem Surg 2007;11(01):66-73

20 Das De S, Johnsen PH, Wolfe SW. Soft tissue complications of dorsal versus volar plating for ulnar shortening osteotomy. J Hand Surg Am 2015;40(05):928-933

21 Koppel M, Hargreaves IC, Herbert TJ. Ulnar shortening osteotomy for ulnar carpal instability and ulnar carpal impaction. J Hand Surg Eur Vol 1997;22(04):451-456

22 McBeath R, Katolik LI, Shin EK. Ulnar shortening osteotomy for ulnar impaction syndrome. J Hand Surg Am 2013;38(02):379-381 